\title{
Os estudos culturais na encruzilhada dos feminismos materiais e descoloniais
}

Claudia de Lima Costa ${ }^{1}$

Atualmente, temos a impressão de estar vivendo no limite. Com o colapso da narrativa do Iluminismo, anunciado pelos críticos do projeto modernista, restaram-nos apenas escombros para construirmos novas histórias que, de certo modo, nos capacitam a dar sentido às realidades atomizadas da vida contemporânea. Nas sequelas do linguísticointerpretativo em torno das ciências sociais, afirmar que não há no mundo objetos linguísticos despidos, mas somente interpretados e contextualizados, tornou-se trivial. A narrativa continua sendo o modo por definição para expressar conhecimento; estratégias retóricas e elementos figurativos intervêm sempre em nosso conhecimento do mundo. No entanto, um renovado enfoque sobre a linguagem e significação levou à formação de uma interdependência tão forte entre vida e língua, experiência e metáfora (Furman, 1985), que as estruturas do mundo se engastaram nas do texto. Mas também se discutiu sobre uma materialidade inerente à realidade, impossível de se reduzir à codificação de jogos linguísticos. Para Raymond Williams o real existe, nomeemo-lo ou não. Como então mediar a relação entre o mundo e o texto? Como dar conta de ambos na organização social do poder? Como ir além dos limites do mundo ou do texto, da economia política ou das práticas culturais, das coisas ou das palavras, sem reduzir um termo a outro?

Neste artigo, proponho-me a comentar, em primeiro lugar, como os estudos culturais e os estudos feministas reagiram frente às questões mencionadas anteriormente, sem perder de vista a mais importante (e frequentemente esquecida) de todas: a política. Não obstante, quero argumentar que o norte mais promissor para a investigação das relações entre cultura, política e poder se acha nas práticas feministas - políticas e culturais (feminist cultural politics) -, e não nos estudos culturais tal como se encontram configurados atualmente na academia. Num segundo momento, analiso a intersecção entre feminismo e pós-estruturalismo, enfocando a discussão (nos Estados Unidos, nos anos 1990) sobre a

\footnotetext{
${ }^{1}$ Doutora em estudos culturais e professora da Universidade Federal de Santa Catarina (UFSC), Florianópolis, SC, Brasil. E-mail: cjlimacosta@gmail.com
} 
controvérsia político-epistemológica entre o feminismo materialista cultural (informado por conceitos pós-estruturalistas) e o feminismo materialista marxista histórico (influenciado pela luta de classes) que marcou a pauta dos debates entre os anos 1980 e 1990. O terceiro momento que exploro está marcado por um retorno das teorias feministas, a partir dos anos 2000, a uma noção de materialidade devidamente reconceitualizada, possibilitando uma saída criativa para o já desgastado embate entre texto e contexto, palavras e coisas. Na última parte deste artigo, teço algumas observações sobre a influência dos feminismos descoloniais na reconfiguração do campo dos estudos culturais feministas. Concluo argumentando que a elaboração de um entendimento mais complexo da cultura e das práticas culturais produz um deslocamento produtivo nos termos do debate, ao mesmo tempo que apresenta questões importantes sobre geopolítica, conhecimento e as lutas culturais.

\section{Os estudos culturais e a centralidade da cultura: termos, textos e contextos}

Falar sobre os estudos culturais supõe como ponto de partida uma definição, e aqui já começam os problemas. De fato, qualquer tipo de delimitação analítica implica sempre uma circunscrição de fronteiras acompanhada por gestos e práticas excludentes. Mas como falar de um campo epistemológico sem delimitar territórios?

$\mathrm{Na}$ vasta literatura sobre os estudos culturais encontramos várias estratégias de definição. Tratarei aqui somente das três que têm sido consideradas de uso mais frequente na literatura. Os estudos culturais podem ser definidos: i) como certa tradição político- intelectual; ii) em relação a disciplinas acadêmicas e paradigmas epistemológicos; ou iii) em relação a seus objetos específicos de estudo.

Em primeira instância, os estudos culturais se referem a uma tradição britânica a partir de una perspectiva cultural marxista marcada pelos escritos de Richard Hoggart, E. P. Thompson e Raymond Williams - que surge nos anos 1960 como reação a uma definição tradicional e erudita de cultura e de crítica cultural. Questionando a identificação de cultura com um conjunto de textos e práticas canônicos, tais autores consideravam a cultura (na acepção antropológica) como um conjunto de "textos vividos" e artefatos culturais - ou seja, as 
maneiras pelas quais as pessoas dão sentido a suas vidas cotidianas e interpretam (e negociam ou subvertem) sua situação no mundo. Trabalhando no âmbito das práticas pedagógicas (alfabetização e educação de adultos), os autores já citados buscavam formas para a democratização dessas práticas, bem como entender como os discursos das agências do governo e das instituições públicas (a mídia inclusa) articulam hegemonias que, por sua vez, são legitimadas pelas relações assimétricas de poder. Seguindo a aproximação materialista (marxista) da cultura e sob a influência de Gramsci (particularmente no caso de Williams), esses autores orientam suas análises para questões de economia política, práticas culturais e ideologia, insistindo sempre na relação entre cultura e poder, e nas formas de subordinação que resultam dessa interação. Com Stuart Hall, a tradição britânica dos estudos culturais se afasta um pouco do enfoque marxista da luta de classes para dedicar maior atenção às discussões sobre o colonialismo, $\mathrm{o}$ racismo, as migrações e os grupos étnicos (Mignolo, 1998). ${ }^{2}$

Quanto à segunda estratégia de demarcação, os estudos culturais se caracterizam como um projeto multitransdisciplinar, inclusive antidisciplinar. Localizados em relação de exterioridade quanto a qualquer disciplina, os estudos culturais tomaram emprestadas metodologias das mais diversas áreas epistemológicas (semiótica, literatura, etnografia, economia política, psicanálise, desconstrução etc.), formando dessa maneira uma espécie de bricolagem que não privilegia nenhuma disciplina ou metodologia em particular. ${ }^{3}$ Os estudos

\footnotetext{
${ }^{2}$ Na elaboração de uma crítica cultural marxista, traçaram-se três axiomas: "primeiro, os processos culturais estão intimamente ligados às relações sociais e a formações de classes, com as divisões sexuais, a opressão, a idade avançada e a estruturação racial das relações sociais, atuando como formas de dependência; segundo, a cultura implica poder e favorece a produção de assimetrias em relação às capacidades dos indivíduos e dos grupos sociais para definir e realizar suas necessidades; terceiro, a cultura não é um campo autônomo nem determinado externamente, mas um lugar de diferenças e lutas sociais" (Davies, 1995, p. 21). Para analisar a contribuição de Hall aos estudos culturais, ver Morley e Kuan-Hsing (1996).

${ }^{3}$ No transcurso de sua história, os estudos culturais - ao analisarem o problema da dialética entre cultura e forças materiais, evitando idealismos ou reducionismos - lançaram mão de diferentes marcos teóricos. Em primeiro lugar, a posição culturalista-humanista que caracterizou os estudos culturais modificou-se a partir das influências do estruturalismo de Lévi-Strauss e de Althusser e, mais tarde, do pós-estruturalismo de Foucault, Lacan e Derrida. Hoje em dia, vemos a influência do discurso pós-colonial, das teorias feministas e queer, do pós-marxismo de Laclau e Mouffe e dos estudos subalternos, para citar apenas algumas das novas tendências. Convém recordar que as posições teóricas defendidas pelos estudos culturais sempre têm sido provisórias e refletem sua postura anticanônica.
} 
culturais propõem uma compreensão de mundo não exclusivamente sob o ponto de vista da cultura, mas de especificidades das relações e lutas culturais. Para uma decodificação da organização do poder, os estudos culturais ultrapassam a esfera da cultura para adentrar, por exemplo, nas relações econômicas, nas estruturas da literatura e da organização social e no campo antropológico da vida cotidiana. Como observa Morris (1997), uma leitura textual de um shopping center que não se comprometa seriamente com as demandas da história, com a economia e sociologia (entre outras) continuará sendo uma leitura textual, e não estudos culturais.

Para Morris, é o contexto que definirá a abordagem metodológica e teórica que deverá ser utilizada. No entanto, como adverte Grossberg (1997b), o contexto deve ser entendido não apenas como pano de fundo de um fenômeno cultural, mas também como algo que faz parte das forças constitutivas desse fenômeno. O contexto é sempre o resultado das relações de poder; e intervir nele nos exige um mapeamento dessas relações a fim de poder desarticulá-las e rearticulá-las em um novo contexto. Por conseguinte, através da inter-relação entre contexto, conhecimento e poder, os estudos culturais podem ser definidos como uma prática (denominada contextualismo radical) que "politiza a teoria e teoriza a política" (Grossberg, 1997b, p. 253). ${ }^{4}$ Em outras palavras, os estudos culturais se recusam a definir a questão da adequação teórica em termos puramente epistemológicos. Seu projeto teórico é sempre avaliado em relação a seu projeto político específico - ou de construção de possibilidades a partir das impossibilidades. Dito de outra forma, os estudos culturais buscam o difícil equilíbrio entre o otimismo da vontade e o pessimismo do intelecto.

Quanto à terceira estratégia de definição proposta, podemos dizer que os estudos culturais lutam contra as estruturas de poder através da articulação da noção de "popular" - entendido lato sensu como a relação que as pessoas têm com o poder em seu cotidiano. Dessa maneira, os estudos culturais não são uma teoria sobre a cultura popular (massiva),

\footnotetext{
${ }^{4}$ Grossberg (1997a) explica que, para poder entender uma prática, seu contexto (tanto histórico como teórico) deve ser reconstruído. O contexto não é algo empiricamente acessível, ou seja, algo assegurado de antemão. $\mathrm{O}$ contexto de uma prática ou de um texto é resultado de um conjunto tão complexo de relações, articulações e rearticulações com outras práticas e textos, que quase sempre se converte em um espaço submerso em contradições, conflitos e lutas. Como pesquisadores/as, somente chegamos ao contexto ao final de nossa análise.
} 
tampouco uma teoria crítica cultural, mas uma crítica da vida cotidiana (Grossberg, 1997a). Sua incumbência mais importante e urgente é a de captar as determinações e inter-relações múltiplas entre formas culturais e forças históricas, sem perder de vista a cumplicidade do/a crítico/a com as estruturas de poder e privilégio nas quais está inserido/a. Nesse sentido, o objeto dos estudos culturais pode caracterizar-se como uma aliança discursiva - "um conjunto de relações entre práticas [textuais ou de outro tipo] mediadas por relações de poder e dispersas em determinado espaço social" (Grossberg, 1997b, p. 257). Traçar os efeitos das práticas e alianças discursivas na vida diária das pessoas constitui o objeto desse campo de conhecimento. Sendo assim, para Grossberg (1997a) os estudos culturais podem começar com a cultura, mas devem terminar fora dela - nas relações de poder (materiais e textuais) que formam o contexto da vida cotidiana das pessoas.

\section{Para além da cultura}

Depois de roubar a noção (não estética) de cultura dos antropólogos e de tê-la expurgado de todo resquício de ortodoxia marxista embasado na prioridade ontológica da luta de classes, os estudos culturais transformaram a cultura em best-seller. Através da especificidade das lutas culturais - ou seja, da noção de cultural politics - os estudos culturais propõem que se volte a enfocar a política através das práticas culturais (Kuan-Hsing, 1996). Cultural politics representa um meio mediante o qual se possibilita o estudo, de maneira não reducionista, das complexas relações entre cultura, política e poder. Trata-se de uma tentativa de abarcar tanto as dimensões políticas da cultura, como as dimensões culturais da política, salientando seus respectivos potenciais emancipatórios.

Não obstante, convém observar que o conceito de cultural politics - que constitui a marca dos estudos culturais - teve seus primeiros usos estratégicos não somente em Gramsci, mas também a partir da noção de revolução cultural (explorada por pensadores socialistas como Frantz Fanon, Lázaro Cárdenas, Amílcar Cabral e José Carlos Mariátegui) como forma de resistência aos poderes coloniais e neocoloniais. A cultura (contra-hegemônica anticolonial) se converte em um meio de unificação das sociedades fragmentadas pelo colonialismo. Segundo Dirlik (apud Young, 1996, p. 112), isso mostra que "os movimentos socialistas 
asiáticos, africanos, centro e sul-americanos foram os primeiros a empregar o conceito de cultural politics e de revolução cultural". Entretanto, como questiona Young, o que acontece quando o conceito de cultural politics é sequestrado de seu locus nas lutas sociais pela academia e pelas editoras? Torna-se mais cultura que política. Enquanto a política é despolitizada e se transforma em questões de discurso e representação, a cultura é textualizada e se transforma em inquietude estética. Contra essa tendência, precisamente, adverte Grossberg (1997a), reiterando que os estudos culturais devem ir mais além da cultura e, nas palavras de Morris (1997), não devem perder de vista nem a política da cultura, nem a política da política.

Essa propensão à textualidade que marcou grande parte das práticas dos estudos culturais nos Estados Unidos sofre atualmente profundas revisões. Há uma chamada generalizada para que os/as praticantes dos estudos culturais devolvam à cultura sua dimensão material e restituam aos estudos culturais sua primazia política. Se, em um determinado momento, e respondendo à influência das teorias pós-estruturalistas, os estudos culturais substituíram coisas (objetos) por palavras, atualmente se vê a necessidade de um movimento inverso - das palavras para a materialidade do mundo -, mas sem sucumbir à visão inocente (prélinguística) das práticas sociais (McRobbie, 1997).

O caminho de volta à materialidade do mundo não é o da construção de oposições binárias entre práticas discursivas e não discursivas, entre práticas significantes e processos sociais, entre o texto e o mundo. Tampouco significa, reitera Stuart Hall, um regresso à materialidade da realidade em um sentido vulgar (Kuan-Hsing, 1996, p. 403). Ir para além da cultura não significa abandonar o momento textual ou tratá-lo como autônomo, pois a cultura somente pode ser apreendida em sua manifestação simbólica. Implica, isso sim, não se deter no texto, no estudo das relações entre produção cultural de um texto e seu consumo (ou entre ideologia, desejo e prazer); na etnografia do local; no estudo da construção do sujeito dentro de sistemas de diferença; ou na política da representação (Grossberg, 1997a). Cultural politics deveria abarcar todos esses pontos e outras coisas mais a fim de poder construir articulações entre a vida cotidiana e seus contextos políticos, as forças sociais e institucionais e as relações de poder. Somente através desse caminho a análise será capaz de abarcar a cultura como um conjunto 
complexo de práticas que excedem os limites textuais e circunscritos das representações simbólicas.

\section{O feminismo e a análise política da cultura}

Desde o principio - quando se constituíram como grupo de investigação do Centro para Estudos da Cultura Contemporânea (Center for Contemporary Cultural Studies - CCCS), em Birmingham, Inglaterra, - as feministas, tal como "ladras noturnas" (Brundson, 1996), revolucionaram muitos dos rumos das investigações em curso ao colocarem a mulher e o gênero na agenda do Centro. Entre as principais consequências imediatas dessa inclusão, ou melhor, interrupção dentro dos estudos culturais está: a valorização da esfera privada e das esferas públicas alternativas (estas mais frequentadas por mulheres, principalmente das "subculturas" de jovens adolescentes das classes trabalhadoras); o deslocamento da categoria de classe como mecanismo primário de dominação (o que abriria espaço para outros vetores de subordinação social); e maior preocupação com questões sobre subjetividade, identidade, sexualidade, desejo e emoção, possibilitando maior compreensão da dominação/subordinação em nível subjetivo. Estudar como a subjetividade se posiciona contraditoriamente fez com que as pesquisadoras compreendessem que as categorias da identidade raramente formam unidades sociais monolíticas; ao contrário, estão sempre em complexa e conflitiva inter-relação com outras identidades e relações de poder (por exemplo, para uma trabalhadora negra lésbica, as categorias gênero, raça, classe e orientação sexual não constituem elementos homogêneos, mas derivam seus significados de outras categorias sociais).

Por último, devido a seu compromisso histórico com o movimento de mulheres (de onde surgiu), para o feminismo a subordinação e a dominação estavam marcadas no próprio corpo, excedendo aí seus limites puramente epistemológicos. Em outras palavras, eram algo mais que categorias analíticas abstratas. Por conseguinte, a insistência na análise das dimensões subjetivas e simbólicas das experiências das mulheres, junto com o projeto político de intervenção nas estruturas do cotidiano dessas mulheres - projeto que orientou desde o princípio as pesquisas feministas dentro do campo dos estudos culturais, tanto na Inglaterra como nos Estados Unidos -, equipou as teorias feministas 
com poderosos instrumentos para "cortar" na materialidade tanto da cultura como do poder. Se, por um lado, como nos mostra Rooney (1996), o entrelaçamento entre teoria e política no feminismo foi forjado histórica e conjunturalmente a partir do compromisso político na luta pela emancipação das mulheres; por outro, o fato de as feministas trabalharem em geral nas "economias nebulosas das fronteiras disciplinares" (Appadurai, 1996, p. 29) e à margem dos cânones deu a elas um matiz antidisciplinar a seus projetos, obrigando-as a desafiar incessantemente práticas acadêmicas e paradigmas dominantes. ${ }^{5}$ Apesar de serem obrigadas a uma existência contra a corrente, viver à margem permitiu às feministas compreender melhor a pluridimensionalidade do poder e da dominação, e a plurivalência das alianças frente às práticas discursivas hegemônicas, o que redundou em maior entendimento das possibilidades de resistência.

O feminismo contemporâneo representa um grande espectro de discursos sobre as relações de poder a partir da economia política da mulher concebida em toda sua diferença interna (sexual, de gênero, de raça, de classe, de "terceiro mundo" etc.). Esses discursos são muitas vezes antagônicos entre si e não se cristalizam em uma única posição. Não obstante, tal heterogeneidade interna - ou, segundo Audre Lorde, "uma interdependência de forças diferentes" - não foi capaz, até o presente, de fragmentar ou debilitar o ímpeto político do feminismo na luta contra a dominação e a exclusão. Pelo contrário, seu compromisso político tanto em nível da biografia como da teoria constitui a principal diferença do feminismo quanto a outros movimentos sociais ou discursos (inclusive os dos estudos culturais). Tal diferença é produto da necessidade histórica do feminismo, primeiramente, de identificar os pontos de reprodução da subordinação social nas estruturas de desigualdade; e segundo, de construir articulações entre seus diversos sujeitos perseguindo metas políticas específicas (Long, 1996, p. 202). ${ }^{6}$

\footnotetext{
${ }^{5}$ Brundson (1996) observa que entre as mulheres que estudaram no CCCS em Birmingham nos anos 1970, nenhuma conseguiu doutorar-se.

${ }^{6}$ Não tenho a intenção de idealizar o feminismo. Já se escreveu muito sobre suas contradições e traições. A bibliografia é tão extensa que seria impossível citá-la em poucas páginas. Na Inglaterra, por exemplo, a edição em 1981 de Feminism for girls, por McRobbie e McCabe, já mostrava os problemas com a categoria "mulher" e as diferenças entre mulheres (Brundson, 1996). Nos Estados Unidos, a coleção organizada por Moraga e Anzaldúa, This bridge called my back (1983), traz os primeiros e mais urgentes debates sobre diferença no interior do próprio movimento feminista. Desde então, muitas outras coleções desse tipo foram publicadas, a partir das mais diversas perspectivas
} 
Apesar da existência de semelhanças e coincidências significativas entre o projeto político dos estudos culturais e o do feminismo, afirmo que as práticas políticas e culturais feministas representam, para os estudos culturais, um exemplo de como articular duplamente a necessidade de intervenção histórica com o imperativo de abstração teórica. Ou seja, se quisermos, como uma vez disse Stuart Hall (1990) quanto à tarefa que se apresenta ao intelectual dentro dos estudos culturais, "alienar as vantagens que nos foram facilitadas pelo sistema, tomar todo o sistema de conhecimento e [...] colocá-lo a serviço de algum outro projeto", creio que encontraremos mais inspiração e orientação na prática dos estudos feministas que na dos estudos culturais.

Mas o que ocorre com o compromisso político das teorias feministas quando fazem alianças comprometedoras com as teorias pósestruturalistas? A seguir farei um breve resumo das controvérsias entre as duas tendências que muito marcaram o debate feminista nos anos 1990 dentro e fora dos estudos culturais: o materialismo cultural (informado por conceitos pós-estruturalistas) e o materialismo histórico (influenciado por um marxismo baseado na primazia da luta de classes). Desejo afirmar que a solução para o problema levantado pelo (des)encontro dessas duas correntes teóricas feministas consiste na elaboração de um entendimento mais complexo da cultura e das práticas culturais (como o que já estava sendo elaborado pelas feministas no campo dos estudos culturais e a partir da preocupação com a materialidade do lugar de enunciação da mulher subalterna).

\section{Os debates feministas na América do Norte nos anos 1990}

No lapso de vinte anos (desde a década de 1970 até 1990), o feminismo ocidental - em todas suas variadas taxonomias (por exemplo, liberal, socialista, marxista, radical, cultural e pósestruturalista) - tem passado por várias mudanças de paradigmas, que, por um lado, revelaram que sua atividade teórica é de natureza contingente, perspectivista, contraditória e historicamente situada e, por outro, ressaltaram seu compromisso político com a luta contra a dominação. Não obstante, ao tentar explicar a causa da opressão das

(feminismo negro, lésbico, queer, do terceiro mundo etc.), que continuaram colocando mais lenha na fogueira e deram forma à heterogeneidade interna do movimento mencionada por Lorde. 
mulheres ao longo das diversas geografias, as feministas nos anos 1970, como Fraser e Nicholson o expressaram (1988), formularam "quase metanarrativas" da opressão feminina. Para Weed (1989), uma profunda contradição ou tensão começou a permear o feminismo ocidental desde o fim dos anos 1970 e ao longo dos 1980. Situado na interseção conflitiva da política de identidade e da crítica pós-estruturalista do humanismo liberal, o feminismo, ao mesmo tempo que endossava a noção de uma identidade feminina universal ancorada nos valores do Iluminismo, como direitos, igualdade e liberdade, empenhava-se na desconstrução do discurso humanista da teoria moderna.

Em vista de algumas afinidades entre o projeto feminista e o desconstrutivista do pós-estruturalismo, essa aliança possibilitou de maneira expressiva uma aproximação mais diferenciada dos problemas da constituição do sujeito, sua subjetividade e seu agenciamento (Best e Kellner, 1991). Mas, apesar dos aspectos positivos do intercâmbio entre essas duas tendências político-culturais, sua colaboração também foi recebida, com certa frequência, com veemente oposição por parte de alguns redutos feministas e com cautelosa reticência por outros. Além disso, há um consenso generalizado de que os dois não podem e não devem fundir-se, caso o feminismo não queira ser submetido ao pósestruturalismo. Posto que tantos são os problemas, apontando em várias direções, minha aproximação aqui será necessariamente sintomática, não exaustiva. Chamarei a atenção para o que considero como mais pertinente ao tema central deste artigo. Expostos esquematicamente, os pontos são os seguintes.

Primeiro, existe a alegação de que a dispersão do sujeito, da história e da filosofia, nos jogos linguísticos, leva consigo a renúncia à subjetividade, aos ideais de autonomia, reflexividade e prestação de contas, todos esses requisitos para qualquer projeto emancipatório. Seyla Benhabib (1995) afirma que, enquanto a subjetividade, a identidade e a agência forem interpretadas como os únicos efeitos das práticas discursivas, seguindo certo fundamentalismo linguístico, o pósestruturalismo e o feminismo permanecem projetos incompatíveis. Para formar-se uma ideia mais politicamente orientada sobre esses temas cruciais, continua Benhabib, temos de olhar para além do círculo hermenêutico (míope) das estratégias narratológicas e da constituição dos significados a fim de explorar processos sociais e estruturais mais amplos. 
Segundo, de acordo com a mesma linha crítica de Benhabib, outras autoras (Bordo, 1990, 1992; Flax, 1990; hooks, 1990), embora seriamente comprometidas com o pós-estruturalismo e com plena consciência do perigo inerente às definições essencialistas da identidade, não estão seguras de aderir totalmente à ideia da fragmentação do sujeito junto com o desgaste da autoridade de sua experiência. Afirmam que o descentramento do sujeito parece levar consigo um brilho positivo apenas na teoria. Na prática e no contexto das lutas de cada dia pela (re)construção do sentido do "eu" e do agenciamento por parte de sujeitos subalternos, o credo teórico e metodológico do pósestruturalismo ameaça esvaziar o feminismo de sua política afirmativa.

Terceiro, a ênfase das teorias feministas pós-estruturalistas sobre a perspectiva sempre já situada dos sujeitos converteu-se em uma plataforma política e epistemológica inalterável, a partir da qual as feministas lançam intensos ataques contra uma série de postulados que correspondem à relação entre observador/a e observado. Superada a pretensão do Iluminismo referente à objetividade do conhecimento e da razão - isto é, "visão de nenhuma parte" (Bordo, 1990, p. 139; Hartsock, 1990, p. 18) -, algumas feministas pós-estruturalistas, excessivamente preocupadas e comprometidas com o pluralismo, a heterogeneidade e o interminável jogo da diferença, acabaram substituindo a nada auspiciosa "visão de nenhuma parte" pela infausta e míope "visão de qualquer parte" (Bordo, 1990).

Em reação às correntes feministas que se entrecruzam com o pósestruturalismo, as feministas do materialismo histórico, alegando que "a luta sobre significados, língua, práticas culturais e política de representação deve basear-se na prioridade das lutas econômicas" (Ebert, 1996, p. 123), exigiram a volta do marxismo ortodoxo e invocaram a contradição entre trabalho e capital para explicar a opressão feminina. No entanto, com o objetivo de chamar a atenção para a economia política do patriarcado capitalista e fazer oposição à expansão do pós-marxismo no feminismo, feministas materialistas mergulharam nas águas turvas do reducionismo econômico. Afastandose do que consideravam como tipos indeterminados de "análises sistêmicas" e insistindo na prioridade da análise causal, algumas feministas materialistas afirmam que, para compreender o porquê da opressão das mulheres, precisamos abandonar o recurso a "categorias abstratas, históricas ou meramente culturais, tais quais desejo, matéria 
ou performatividade" (Hennessy e Ingraham, 1997, p. 2) em favor de um novo enfoque nos efeitos diretos do sistema capitalista de classe na vida das mulheres. $\mathrm{Na}$ hierarquia do feminismo materialista de determinação causal, as mulheres ditas "do terceiro mundo" ocupavam um lugar único (certamente nada invejável). Devido à exploração e opressão (que padecem), não podem dar-se ao luxo nem aos prazeres da política lúdica pós-classe dirigida a uma liberdade semiótica. A essas empobrecidas mulheres lhes atribuíram o árduo trabalho (nem mais, nem menos!) de conectar "a política cultural com a luta revolucionária para mudar fundamentalmente as condições de produção, apropriação do excedente de trabalho e da desigual distribuição da riqueza" (Ebert, 1996, p. 124).

Apesar da valiosa contribuição de Ebert e Hennessy para deter o que percebiam como a desconstrução de grande parte da teorização feminista ocidental (onde, segundo elas, tudo o que é sólido começa a derreter-se), houve a necessidade de escapar da dupla armadilha que havia aprisionado até então os debates entre feminismo pósestruturalista contra o feminismo histórico-materialista, libertação libidinal contra revolução.

Se, por um lado, as feministas materialistas situadas no Norte global reduziam a mulher pobre do Sul global a uma longa lista de carências, ao mesmo tempo que as transformavam em guardiãs da prática revolucionária utópica (sem nenhuma pausa para os prazeres de uma política do ciborgue), por outro, feministas da tendência pósestruturalista e pós-marxista optavam pela rota mais fácil ao dissolver as necessidades materiais das mulheres em jogos de linguagem. Uma maneira de evitarmos essa cilada e desmantelarmos o binarismo problemático entre linguagem/realidade requer concebermos a realidade como uma estrutura de planos múltiplos de efeitos (materiais, libidinais, afetivos, semióticos) implementados pelas práticas que atravessam, intersectam e interrompem umas às outras (Grossberg, 1992). As práticas, que não possuem uma essência inerente, se estruturam a partir de seus efeitos, os quais jamais são garantidos de antemão, porém sempre reais e efetivos. Para Grossberg, da mesma forma que as práticas econômicas surtem efeitos para além da esfera econômica, os efeitos das práticas culturais podem ir mais além da significação ou mesmo passar longe dela. É a articulação, e não apriorismos tais como os defendidos pelas feministas materialistas ou pelas feministas pós-estruturalistas, que constrói inter-relações entre 
práticas e seus efeitos, necessidades e afetos, interligando-as ao contexto sociopolítico mais amplo.

Na próxima seção discuto a emergência do feminismo material, a partir dos anos 2000, como alternativa aos impasses entre feminismo pós-estruturalista desconstrucionista e feminismo histórico-materialista em suas respectivas abordagens da dicotomia entre materialidade/realidade e linguagem, natureza/cultura.

\section{Feminismos materiais}

Em resposta ao então chamado de McRobbie para um retorno das palavras às coisas, no final dos anos 1990 e a partir do século XXI, teóricas feministas situadas nos mais distintos lugares disciplinares, tais como Elizabeth Grosz, Claire Colebrook, Karen Barad, Donna Haraway, Stacy Alaimo, Susan Bordo, Susan Hekman, entre outras, defendem uma abordagem que possa trazer a natureza de volta para a cultura. Essas autoras exploram criativamente as articulações complexas entre o material e o discursivo de forma que o feminismo possa novamente lidar com a materialidade do corpo e da experiência sem abrir mão do fato de que corpos/experiências são culturalmente/discursivamente constituídos, mas que não se exaurem nessa discursividade. A ênfase no modelo do construcionismo social fez com que o feminismo se concentrasse por demasiado no polo discursivo da realidade e não explorasse o suficiente o que Barad (2003) denomina de "intraatividade" entre o material e o discursivo. Para Barad, apesar de sabermos que os fenômenos não existem independentemente dos instrumentos que os observam - já que são em parte produzidos por esses instrumentos -, devemos entender como os fenômenos (nesse caso, a matéria), por sua vez, interferem nos instrumentos de observação, também os materializando. Portanto, em vez de vermos a natureza passivamente recebendo o agenciamento da cultura, precisamos concebê-las em sua inseparabilidade ontológica (natureculture, para Haraway), desafiando, assim, as fronteiras entre o humano e o não humano. Segundo Barad,

Muito poder foi concedido à linguagem. A virada linguística, a virada semiótica, a virada interpretativa, a virada cultural: parece que, ultimamente, a cada virada qualquer coisa - até a 
materialidade - vira uma questão de linguagem ou de representação cultural (Barad, 2003, p. 801).

Indo a contrapelo dessas viradas, a autora propõe uma ontoepistemologia (estudo das práticas de saber) que busca integrar os avanços do construcionismo social e do pós-estruturalismo com um novo entendimento de materialidade, a qual ela chama de realismo agencial (agential realism). A virada material, junto com a abordagem ontoepistemológica, aponta com conviç̧ão para o fato de que há um mundo lá fora, ainda que nosso acesso a ele seja pela linguagem. É através de nossos conceitos que conhecemos o mundo, porém o mundo também age na formação de nossos conceitos, moldando-os e limitando-os, cujas consequências são também materiais/reais.

Gostaria, no que se segue, explorar como os debates feministas sobre o retorno da materialidade, do real, reconfiguram noções pósestruturalistas do sujeito e da experiência, bem como as implicações para o conceito de identidade e para as políticas identitárias, sempre temas tão caros aos estudos culturais.

Susan Hekman (2008) argumenta que é na arena da construção do sujeito e da identidade que as propostas da virada material encontram seu maior desafio, já que nada pode ser mais permeado pela linguagem do que a noção de sujeito. Feministas que se debruçam sobre questões da corporeidade argumentam que sujeitos não são apenas constituídos por discursos, mas também por corpos que pesam (Elizabeth Grosz, Moira Gatens, Susan Bordo, Suzanne Bost, para citar apenas algumas). Nesses trabalhos, o corpo não é um elemento passivo à espera de sua inscrição social, mas uma materialidade aberta e recalcitrante, uma montagem de tecnologias, matérias, discursos e outros elementos não humanos - enfim, uma interespécie (Haraway, 2003). Certamente um dos exemplos mais citados desse tipo de reflexão sobre o corpo (e, consequentemente, sobre o sujeito e a identidade) se encontra nos escritos de Gloria Anzaldúa, para citar um caso específico, e de um número de outras autoras latinas/chicanas/latino-americanas, queers, de cor situadas em lugares ex-cêntricos, onde a dura materialidade da desigualdade e da exclusão resistiu às performances paródicas das palavras. ${ }^{7}$

As implicações para os estudos culturais desse novo paradigma articulado pelas feministas da virada material são, de fato, profundas.

\footnotetext{
${ }^{7}$ Para uma discussão sobre a questão da materialidade em Gloria Anzaldúa, veja Costa e Ávila (2005).
} 
Por um lado, quebram definitivamente com a concepção da linguagem como representação, seja a que vigorou na modernidade (a linguagem como espelho da natureza), seja a que prevaleceu na pós-modernidade (a linguagem como constitutiva da realidade), e há uma busca pelas maneiras inventivas de articular a linguagem com a realidade no sentido de vê-la como reveladora da realidade (a linguagem como propiciando uma abertura para a realidade). ${ }^{8} \mathrm{Um}$ espaço também é criado para as teorias da não representação (como livremente traduzi o termo non-representational theories), as quais, segundo seu mais conhecido articulador, Nigel Thrift (2007), em vez de se prender nos emaranhados da representação e da significação, enfatizam o fluxo da vida cotidiana em suas dimensões precognitivas, ou seja, os aspectos precognitivos da vida encorpada. Portanto, as teorias pósrepresentacionais tentam apreender a relacionalidade tanto dos corpos quanto do mundo em suas potências de ação e interação constantes. Como corolário, questões sobre afeto e afetividade também passam a ser priorizadas nos estudos culturais. Para Massumi (2002, p. XVII), "o afeto não se refere a um sentimento pessoal, ao contrario, é uma intensidade pré-individual que corresponde à passagem de um estado corpóreo para outro, o que implica um aumento ou diminuição da capacidade de ação desse corpo".

É claro que essas implicações também respingam na teorização feminista do sujeito, da identidade e da experiência para além das performances linguísticas. ${ }^{9} \mathrm{Na}$ ótica das feministas que trabalham com narrativas dentro dos estudos culturais, as novas discussões sobre materialidade, identidade, experiência, bem como sobre a interrelacionalidade entre corpo e mundo (entre humano e não humano), são promissoras por vários motivos, dos quais destaco dois. Primeiro, resgatam a importância dos relatos sobre experiência, principalmente daquelas mulheres subalternas, dando-lhe estatura epistemológica e política. Importa - e muito - quem fala e a partir de qual lugar material. Esses relatos, muito deles feitos a partir da prática do testemunho e/ou

\footnotetext{
${ }^{8}$ Há aqui um retorno a Wittgenstein, que já apontava para a inter-relação complexa entre linguagem e realidade. Segundo Wittgenstein, a linguagem não constituiu o mundo, mas nos possibilita habitálo conforme os parâmetros de nossa existência como seres humanos.

${ }^{9}$ Para uma análise perspicaz sobre a primazia dada ao afeto nos estudos culturais contemporâneos como perspectiva privilegiada a partir da qual interpretamos o mundo e nosso(s) respectivo(s) lugar(es), ver Hemmings (2005).
} 
da narrativa autobiográfica - e que já haviam sido duramente atacados por alguns praticantes dos estudos culturais nos anos 1990, desencantados com o que interpretavam como as promessas falidas desse gênero literário-, 10 adquiriram nova força epistêmica. As identidades corporificadas e os relatos de experiência desses sujeitos constituem modos de saber que podem desafiar os mecanismos que as oprimem e as excluem dos registros sociais. ${ }^{11}$ Segundo, são os relatos sobre a experiência que configuram nossas teorias e conhecimentos do mundo. Teorizar é uma forma de narrar histórias sobre nós e sobre a materialidade do mundo que nos rodeia. Os ensaios publicados em Material feminisms argumentam com pungência a favor de uma mudança paradigmática da concepção de identidade como efeito da pura construção social para um relato realista da própria identidade, algo que, por exemplo, os zapatistas já articulavam ao definir suas identidades como "produto de 500 anos de lutas" (Hames-García, 2008, p. 331). Nessas abordagens, as dicotomias entre natureza/cultura, realidade/linguagem são finalmente superadas. Nas palavras de Olivia P. Banner (2009, p. 715), em sua resenha sobre Material feminisms,

Pensar por meio da materialidade da experiência corporal, e entender como ela é traduzida através das construções sociais, está propiciando novas e valiosas maneiras de pensarmos sobre a identidade e coalizão, sobre a inter-relação do corpo e da teoria. Contra o dogma pós-estruturalista de que a subjetividade é uma categoria vazia do humanismo, essas contribuições sugerem que a identidade não é apenas uma construção cultural; pelo contrário, que essas construções culturais têm impacto imediato sobre a forma pelas quais as pessoas experienciam e vivem as suas vidas diárias.

A "virada material", junto com a abordagem ontoepistemológica (Barad, 2003), aponta com convicção para o fato de que há um mundo lá fora, ainda que nosso acesso a ele seja pela linguagem. É através de nossos conceitos - sempre equivocações - que conhecemos o mundo, porém o mundo, longe de ser passivo e objeto de nosso olhar, também age na formação de nossos conceitos, moldando-os e limitando-os, cujas

\footnotetext{
${ }^{10}$ Ver, por exemplo, os ensaios em Gugelberger (1996), bem como Moreiras (2001).

${ }^{11}$ Parta citar um exemplo, temos o recente interesse por textos que haviam sido "esquecidos" pela crítica, como Quarto de despejo (2010), de Carolina Maria de Jesus. Friso também a bela narrativa de Conceição Evaristo em Becos da memória (2006).
} 
consequências são também materiais/reais. Na próxima seção argumento que vejo ecos do que as feministas materiais defendem nas propostas cosmopolíticas para um feminismo descolonial. Defendo que a articulação dessas propostas (uma advinda dos debates no Norte e a outra do Sul) pode servir de estímulo para repensarmos - e descolonizarmos - as práticas dos estudos culturais na América Latina.

\section{Cosmopolítica, geo-corpo-política e o desafio dos feminismos descoloniais}

Um artigo que marcou uma posição significativa nos debates antropológicos sobre a virada ontológica e o questionamento da dicotomia humano/não humano, Marisol de La Cadena (2010) analisa como as comunidades indígenas andinas articularam a presença de criaturas da terra (earth beings), ${ }^{12}$ tais como montanhas sagradas, rios, pedras e animais nos seus protestos sociais contra uma companhia de mineração que queria explorar a montanha próxima do vilarejo onde viviam, trazendo tais criaturas para a esfera de uma política até então reservada às questões unicamente humanas. A autora argumenta que a introdução dessas criaturas não humanas na política subverte a distinção ontológica entre humanidade (cultura) e natureza, que, por sua vez, sempre foi a marca da modernidade ocidental. Earth practices, tais como levar em consideração os desejos e necessidades políticas das criaturas da terra, encenam o respeito e afetos necessários para a manutenção da relacionalidade entre humanos e seus outros (os não humanos) nas comunidades andinas. Inserir essas práticas terrenas nos protestos sociais (isto é, expressar o que essas criaturas reivindicam no bojo das manifestações sociais), nos convida, nas palavras de Isabelle Stengers (2005), a "'desacelerar' a reflexão" ("slow down" reasoning), ${ }^{13}$ já que nos coloca diante de uma ruptura epistêmica

\footnotetext{
${ }^{12}$ Earth beings, nos discursos da política ou ciência ocidental, se referem a seres ou "recursos" naturais que existem separadamente dos humanos. Na cosmologia indígena, o termo significa aqueles outros seres que vivem na natureza e que sempre têm interagido com os humanos, dos quais são parte constitutiva. No texto de Cadena (2010), earth beings significam montanhas sagradas que demandam respeito dos humanos e dos outros não humanos, incluindo animais, plantas e outras criaturas menores, como lagos, florestas e montanhas.

${ }^{13}$ Segundo Stengers (2005), 'slow down' reasoning se refere à criação de um novo espaço para a reflexão a partir de sua desaceleração, criando assim a possibilidade de uma nova consciência dos problemas e situações que nos mobilizam.
} 
muito significativa. Segundo Cadena (2010), a esfera da política sempre se configurou como ontologicamente distinta da esfera da natureza, e tal diferença foi $o$ elemento principal para $o$ desaparecimento de mundos pluriversais, entendidos como mundos sociais heterogêneos e parcialmente conectados, negociando politicamente suas discordâncias ontológicas. Com a reintrodução das criaturas da terra na política, assistimos à emergência do que a autora denominará de cosmopolitismo indígena: ${ }^{14}$ temos a possibilidade, primeiro, de abrir espaços para um tipo de pensamento que nos permite desaprender/desfazer a violência ontológica representada pelo dualismo natureza/cultura (nos permitiria “'desacelerar' a reflexão"); e, segundo, entender que há diferentes perspectivas de diferentes mundos - e não visões diferentes de um mesmo mundo.

Vejo afinidades importantes e ecos significativos entre o que as feministas materiais estão teorizando e as propostas cosmopolíticas para um feminismo descolonial. Introduzindo criaturas da terra (earth beings) e materialidades agenciais na epistemologia ocidental - e subvertendo a dicotomia colonial natureza/cultura -, o cosmopolitismo indígena produz uma desaceleração do pensamento que, por sua vez, ao descolonizar a percepção, possibilita uma abertura para outros saberes e outros mundos pluriversais. Segundo Márgara Millán (2011, p. 26),

$\mathrm{O}$ processo de descolonização do feminismo ou dos feminismos implica um envolvimento em e com os mundos dos sujeitosmulheres subalternizados, um reconhecimento de suas lógicas culturais, e, pelo menos, a disposição de pensar em uma relação diferente entre o humano e o não humano. Uma predisposição a realizar o pachakutit5 como parte da luta feminista. Não é uma tentativa de recuperar raízes estéticas e autenticadas em sua pureza, mas de atualizar distintas formas de ser e estar no mundo para com isso diminuir a força fundante que o capitalismo inflige à nossa cotidianidade presente.

Para Mignolo (2012), pensar em termos de uma geo-corpo-política significa articular as categorias básicas de uma epistemologia da fronteira

\footnotetext{
${ }^{14}$ Cadena toma esse termo emprestado de Stengers (2005). "Cosmos" se refere ao desconhecido constituído a partir de mundos divergentes e múltiplos; "política" significa a articulação que tais mundos seriam capazes de fazer.

${ }^{15}$ Pachakuti, na tradição andina aimará, significa derrubar o mundo atual ou voltar a colocá-lo sobre seus pés: é uma crítica radical contundente da modernidade capitalista (Millán, 2011, p. 26).
} 
(um saber outro, não apenas um outro saber) como primeiro passo para o processo de descolonização. Essa fronteira/zona de contato/zona de exclusão constitui o lugar da ferida colonial que marca, por exemplo, tanto o feminismo de Anzaldúa quanto o de Lélia Gonzalez.

Como curandeira-escritora-poeta, Anzaldúa (2009) trabalha com as metáforas pelas quais apreendemos o mundo para, substituindo-as, descolonizarmos nossos sentidos: o projeto almeja trocar as metáforas negativas que construíram a alteridade dos sujeitos subalternos nos contextos coloniais (e que foram por estes internalizadas) por imagens empoderadoras. A descolonização da percepção, dos sentimentos e da própria linguagem não é possível sem o processo de cura, através de imagens transformadoras, e necessariamente também requer um projeto de tradução/traição do saber/sentir/experienciar hegemônicos a partir do lugar geo-corpo-político da indígena e da mestiça subalternas. Na perspectiva da poeta xamã, tudo o que escrevemos, dizemos ou fazemos afeta o mundo humano e não humano. A cura descolonial de Anzaldúa pressupõe, para Keating (2009), a articulação de uma ontologia bastante complexa que reflete, avant la lettre, os mais recentes debates sobre ontoepistemologias, realismo especulativo e as críticas aos limites do pós-estruturalismo.

Traçando um paralelo com a intervenção de(s)colonial de Anzaldúa a partir da ferida colonial entre México e Estados Unidos, mais ao sul do continente as contribuições da intelectual diaspórica e feminista negra brasileira Lélia Gonzalez para a amefricanização do feminismo articulam, na análise abrangente de Cardoso (2012), os elementos-chave de uma epistemologia descolonial. Cardoso (2012, p. 115) reflete que:

Gonzalez foi uma "intelectual diaspórica, com um pensamento erigido por meio de trocas afetivas e culturais, ao longo do chamado Atlântico Negro, com intelectuais, amigos e ativistas da América do Norte, Caribe e África Atlântica". Deste diálogo com várias(os) autoras(es), realizava a "política de tradução de teorias" para desenvolver um pensamento globalizado e transnacional, voltado, não só para explicar como se formou nas Américas uma matriz de dominação sustentada pelo racismo, mas, principalmente, para intervir e transformar essa realidade a partir de sua compreensão.

O conceito de amefricanidade, introduzido por Gonzalez a partir de uma outra ferida colonial (a experiência de colonização/extermínio dos 
povos indígenas e a vivência diaspórica dos/as negros/as), recupera as lutas de resistência à colonialidade do poder por parte desses povos para, conectando-os, tal qual a prática de curandeirismo de Anzaldúa, articular um pensar "as culturas indígenas e africanas 'desde dentro' e, assim, afastar-se cada vez mais de interpretações centradas na visão de mundo do pensamento moderno europeu" (Cardoso, 2012, p. 118). Elaborando conceitos que provocam o pachakuti como parte da luta pela descolonização do pensamento, Gonzalez brinca com a linguagem, tal qual Anzaldúa, hibridizando-a no que chamará de pretuguês.

Nas palavras de Butler (2004, p. 228), a mediação tradutória de Anzaldúa (e acrescentaria, a de González), cruzando incessantemente mundos e identidades, questiona certezas epistemológicas e nos mostra que "é somente através de existirmos no modo da tradução, da constante tradução, que teremos alguma chance de produzir um entendimento multicultural [leia-se, pluriversal] das mulheres ou, de fato, da sociedade [leia-se, do pluriverso]". As intervenções tradutórias desses sujeitos ex-cêntricos, a partir de outros saberes e outras geo-corpo-políticas, representam uma significante contribuição para renovação/descolonização dos estudos culturais. No entanto, gostaria de concluir com uma ponderação um tanto incômoda. Há um sentimento generalizado de que a tarefa que sempre desafiou a teoria feminista, inclusive nos estudos culturais - a de representar a outra se tornou uma impossibilidade epistemológica, ou seja, está sempre permeada por um fracasso cognitivo. Até que ponto é possível “escrever/representar a outra sem aplainar sua complexidade conjuntural? Não penso que tenhamos respostas fáceis a esse dilema. Talvez haja alguma esperança se seguirmos o então conselho de Visweswaran (1994), isto é, fazer uma constante mediação entre dois momentos - o do inevitável fracasso cognitivo e, quem sabe, o de algum tipo de êxito - de forma que possamos transformar, sempre quando viável, a impossibilidade em possibilidade. Sem admitirmos a inevitabilidade da equivocação, sem adentrarmos na prática da tradução e, concomitantemente, sem nos permitirmos o desacelerar da reflexão diante de mundos pluriversais, aos novos estudos culturais, feministas ou não, só restará a impossibilidade. 


\section{Referências}

ANZALDÚA, Gloria (2009). Metaphors in the tradition of the Shaman. In: KEATING, Ana Louise (Ed.). The Gloria Anzaldúa reader. Durham: Duke University Press.

APPADURAI, Arjun (1996). Modernity at large: cultural dimensions of globalization. Minneapolis: University of Minnesota Press.

BANNER, Olivia P. (2009). Book Review. Signs, v. 34, n. 3, p. 713-717.

BARAD, Karen (2003). Posthumanist performativity: toward an understanding of how matter comes to matter. Signs, v. 28, n. 3, p. 801-831.

BENHABIB, Seyla (1995). Subjectivity, historiography, and politics: reflections on the feminism/postmodernism exchange. In: BENHABIB, Seyla et al. (Eds.). Feminist contentions: a philosophical exchange. New York: Routledge.

BEST, Steven; KELLNER, Douglas (1991). Postmodern theory: critical interrogations. New York: The Guilford Press.

BORDO, Susan (1990). Feminism, postmodernism, and gender-skepticism. In: NICHOLSON, Linda (Ed.). Feminism/postmodernism. New York: Routledge.

BORDO, Susan (1992). Postmodern subjects, postmodern bodies. Review Essay. Feminist Studies, v. 18, n. 1, p. 159-175.

BRUNDSON, Charlotte (1996). A thief in the night: stories of feminism in the 1970s at CCCS. In: MORLEY, David; KUAN-HSING, Chen (Eds.). Stuart Hall: critical dialogues in cultural studies. New York: Routledge.

BUTLER, Judith (2004). Undoing gender. New York: Routledge.

CARDOSO, Claudia Pons (2012). Outras falas: feminismos na perspectiva de mulheres negras brasileiras. Tese (Doutorado) - Programa de Pós-Graduação em Estudos de Gênero, Mulher e Feminismo, Universidade Federal da Bahia, Salvador.

COSTA, Claudia de Lima; ÁVILA, Eliana (2005). Gloria Anzaldúa, a consciência mestiça e o "feminismo da diferença". Revista Estudos Feministas, v. 13, n. 3, p. 691-703.

DAVIES, Ioan (1995). Cultural studies and beyond: fragments of empire. New York: Routledge.

DE LA CADENA, Marisol (2010). Indigenous cosmopolitics in the Andes: conceptual reflections beyond 'politics'. Cultural Anthropology, v. 25, n. 2, p. 334-370.

EBERT, Teresa (1996). Ludic feminism and after: postmodernism, desire, and labor in late capitalism. Ann Arbor: University of Michigan Press. 
EVARISTO, Conceição (2006). Becos da memória. Belo Horizonte: Mazza.

FLAX, Jane (1990). Thinking fragments: psychoanalysis, feminism, postmodernism in the contemporary West. Berkeley: University of California Press.

FRASER, Nancy; NICHOLSON, Linda (1988). Social criticism without philosophy: an encounter between feminism and postmodernism. In: ROSS, Andrew (Ed.). Universal abandon? The politics of postmodernism. Minneapolis: University of Minnesota Press.

FURMAN, Nelly (1985). The politics of language: beyond the gender principle? In: GREENE, Gayle; KHAN, Coppelia (Eds.). Making a difference: feminist literary criticism. New York: Methuen.

GROSSBERG, Lawrence (1992). We gotta get out of this place: popular conservatism and postmodern culture. New York: Routledge.

GROSSBERG, Lawrence (1997a). Bringing it all back home: essays on cultural studies. Durham: Duke University Press.

GROSSBERG, Lawrence (1997b). Cultural studies, modern logics, and theories of globalization. In: McROBBIE, Angela (Ed.). Back to reality? Social experience and cultural studies. Manchester: Manchester University Press.

GUGELBERGER, Georg M. (Ed.) (1996). The real thing: testimonial discourse and Latin America. Durham: Duke University Press.

HALL, Stuart (1990). The emergence of cultural studies and the crisis of the humanities. October, v. 53, p. 11-23.

HAMES-GARCÍA, Michael (2008). How real is race? In: ALAIMO, Stacy; HEKMAN, Susan (Eds.). Material feminisms. Bloomington: Indiana University Press.

HARAWAY, Donna (2003). The companion species manifesto: dogs, people, and significant others. Chicago: Prickly Paradigm Press.

HARTSOCK, Nancy (1990). Postmodernism and political change: issues for feminist theory. Cultural Critique, v. 14, p. 15-33.

HEKMAN, Susan (2008). Constructing the ballast: an ontology for feminism. In: ALAIMO, ALAIMO, Stacy; HEKMAN, Susan (Eds.). Material feminisms. Bloomington: Indiana University Press.

HEMMINGS, Claire (2005). Invoking affect: cultural theory and the ontological turn. Cultural Studies, v. 19, n. 5, p. 548-567.

HENNESSY, Rosemary; INGRAHAM, Chris (1997). Introduction. In: (Eds). Materialist feminism: a reader in class, difference, and women's lives. New York: Routledge. 
HOOKS, bell (1990). Yearning: race, gender, and cultural politics. Boston: South End Press.

JESUS, Maria Carolina de (2010). Quarto de despejo: diário de uma favelada. 9. ed. São Paulo: Ática.

KEATING, Ana Louise (Ed.) (2009). The Gloria Anzaldúa reader. Durham: Duke University Press.

KUAN-HSING, Chen (1996). Post-marxism: between/beyond critical postmodernism and cultural studies. In: MORLEY, David; KUAN-HSING, Chen (Eds.). Stuart Hall: critical dialogues in cultural studies. New York: Routledge.

LONG, Elizabeth (1996). Feminism and cultural studies. In: STOREY, John (Ed.). What is cultural studies? New York: Arnold.

MASSUMI, Brian (2002). Parables for the virtual: movement, affect, sensation. Durham: Duke University Press.

McROBBIE, Angela (1997). Introduction. In: (Ed.). Back to reality? Social experience and cultural studies. Manchester: Manchester University Press.

MIGNOLO, Walter (1998). Interview: a cultural studies questionnaire. Journal of Latin American Cultural Studies, v. 7, n. 1, p. 111-119.

MIGNOLO, Walter (2012). Decolonizing Western epistemology/building decolonial epistemologies. In: ISASI-DÍAZ, Ada María; MENDIETA, Eduardo (Eds.). Decolonizing epistemologies: Latina/o theology and philosophy. New York: Fordham University Press.

MILLÁN, Márgara (2011). Feminismos, postcolonialidad, descolonización: ¿Del centro a los márgenes? Andamios, v. 8, n. 17, p. 11-36.

MORAGA, Cherrie; ANZALDÚA, Gloria E. (1983). This bridge called my back. New York: Kitchen Table Women of Color Press.

MOREIRAS, Alberto (2001). The exhaustion of difference: the politics of Latin American cultural studies. Durham: Duke University Press.

MORLEY, David; KUAN-HSING, Chen (Eds.) (1996). Stuart Hall: critical dialogues in cultural studies. New York: Routledge.

MORRIS, Meaghan (1997). A question of cultural studies. In: McROBBIE, Angela (Ed.). Back to reality? Social experience and cultural studies. Manchester: Manchester University Press.

ROONEY, Ellen (1996). Discipline and vanish: feminism, the resistance to theory, and the politics of cultural studies. In: STOREY, John (Ed.). What is cultural studies? New York: Arnold. 
STENGERS, Isabelle (2005). The cosmopolitical proposal. In: LATOUR, Bruno; WEIBEL, Peter (Eds.). Making things public: atmospheres of democracy. Cambridge: MIT Press.

THRIFT, Nigel (2007). Non-representational theory: space, politics, affect. New York: Routledge.

VISWESWARAN, Kamala (1994). Fictions of feminist ethnography. Minneapolis: University of Minnesota Press.

WEED, Elizabeth (1989). Introduction: terms of reference. In: WEED, Elizabeth (Ed.). Coming to terms: feminism, theory, politics. New York: Routledge.

YOUNG, Robert J. C. (1996). Torn halves: political conflict in literary and cultural theory. Manchester: Manchester University Press.

Recebido em abril de 2014.

Aprovado em julho de 2014.

\section{resumo/abstract}

\section{Os estudos culturais na encruzilhada dos feminismos materiais e descoloniais}

Claudia de Lima Costa

Neste artigo, refaço a trajetória dos debates nos estudos culturais feministas, principalmente nos Estados Unidos, tendo como foco três tipos de abordagem em relação às dicotomias realidade/representação e texto/contexto. Como apreender a materialidade do mundo sem abrir mão do fato de que nossas narrativas/representações são sempre constitutivas desse mundo? Argumento que vejo ecos do que as feministas materiais defendem nas propostas cosmopolíticas latino-americanas para um feminismo descolonial. Alego que a articulação desses dois projetos (um advindo dos debates no Norte e o outro do Sul) pode servir de inspiração para repensarmos - e descolonizarmos - as práticas dos estudos culturais na América Latina.

Palavras-chave: estudos culturais, teorias feministas, materialismo, cosmopolítica, feminismos descoloniais. 


\section{Cultural studies at the crossroads between material and decolonial feminisms}

\section{Claudia de Lima Costa}

In this article, I retrace the trajectory of the debates in feminist cultural studies, particularly in the United States, focusing on three types of approaches to the dichotomies reality/representation and text/context. How to grasp the materiality of the world without giving up the fact that our narratives/representations are always already constitutive of that world? I see echoes of what material feminists advocate vis-à-vis the thorny issue of the materiality of the world in the cosmopolitical proposals advanced by Latin American decolonial feminisms. I claim that the articulation of these two projects (one derived from debates in the North and the other from the South) can serve as an inspiration to rethink - and decolonize - the practices of cultural studies in Latin America.

Keywords: cultural studies, feminist theories, materialism, cosmopolitics, decolonial feminisms. 